\title{
Where We are Today: The Role of Computed Tomography Angiography in Diagnosing Coronary Artery Disease-from Guidelines Point of View
}

\author{
Laura Zajančkauskienė ${ }^{1 *}$, Eglẻ Montrimavičienë ${ }^{2}$, Antanas Jankauskas ${ }^{3}$, Kristina Morkūnaitė \\ and Gintarẻ Šakalytë ${ }^{1}$ \\ ${ }^{1}$ Department of Cardiology, Medical Academy, Lithuania \\ ${ }^{2}$ Medical Academy, Lithuania \\ ${ }^{3}$ Department of Radiology, Medical Academy, Lithuania \\ *Corresponding author: Laura Zajančkauskienė, Department of Cardiology, Medical Academy, Lithuanian University of Health \\ Sciences, Lithuania
}

\begin{tabular}{|c|c|}
\hline ARTICLE INFO & ABSTRACT \\
\hline Received: & Abbreviations: CAD: Coronary Artery Disease; ESC: European Society of Cardiology; \\
\hline Published: November 05, 2019 & $\begin{array}{l}\text { PTP: Pre-Test Probability; ICA: Invasive Coronary Angiography; CTA: Cardiac Computed } \\
\text { Tomography Angiography; CCS: Chronic Coronary Syndromes; CACS: Coronary Artery }\end{array}$ \\
\hline
\end{tabular}

Citation: Laura Zajančkauskienè, Eglè Montrimavičienè, Antanas Jankauskas, Kristina Morkūnaitè, Gintarè Šakalytè. Where We are Today: The Role of Computed Tomography Angiography in Diagnosing Coronary Artery Diseasefrom Guidelines Point of View. Biomed J Sci \& Tech Res 22(3)-2019. BJSTR. MS.ID.003767.

\section{Introduction}

Coronary artery disease (CAD) remains a leader in cause of mortality in high income countries and there are no promising data that it will change soon [1]. In newly published 2019 European Society of Cardiology (ESC) guidelines [2] the importance of choice in diagnostic tool is highlighted. The choice is often based on pretest probability (PTP) [2,3]. However, in clinical practice we can still see excessive use of invasive coronary angiography (ICA) with less than $50 \%$ of them diagnosing obstructive CAD [4]. This gives an idea that we have to look for a better non-invasive diagnostic test to reduce the number of ICA. The diagnosis of CAD can be confirmed by either anatomical or functional non-invasive tests. A meta-analysis has shown that different diagnostic tests have different optimal performance range based on anatomical and functional significance of CAD [3]. PROMISE and SCOT-HEART are two major randomized clinical trials that have shown a benefit of cardiac computed tomography angiography (CTA) in diagnosing CAD $[5,6]$. In this paper we will look where CTA stands in the main international guidelines today.

ESC

A newly released chronic coronary syndromes (CCS) guidelines are focusing on diagnostic and management issues [2]. For patients who could not be referred either to low or to high clinical likelihood (PTP) of CAD, non-invasive functional and anatomical diagnostic tests are suggested. Functional testing is based on visualization of ischemic zones in myocardium and is best to rule-in CAD. However, excessive atherosclerosis without obstruction could be missed by functional tests - guidelines remind. From this point of view, CTA as the main anatomical test is superior to functional tests. On the other hand, CTA cannot evaluate the burden of ischemia alone. 
Which test to choose, guidelines recommend to decide based on local experience, availability and patients characteristic (radiation, contrast agents, etc.). It is recommended to use CTA:

a. In lower probability of CAD cases.

b. In patients without previously diagnosed CAD.

c. As alternative to ICA, when other non-invasive tests are inconclusive.

d. In patients with presumable good imaging quality (regular heart rate, no significant obesity, ability to hold breath, no excessive coronary calcification).

CTA not only can reliably help to rule out CAD in both anatomical and functional ways [7] but can also show asymptomatic atherosclerosis. According to new ECS CCS guidelines before making a decision on revascularization you have to have information from both: anatomical and ischemic testing. Coronary artery calcium score (CACS) is only mentioned as it should not be used to identify obstructive $\mathrm{CAD}$, on the other hand it could be useful for risk modification, changing the course of disease. In addition, zero Agatston score is associated with low probability of obstructive CAD $(<5 \%)$ - suitable for ruling-out the diagnosis [8].

\section{NICE}

British medical society favors CTA as primary diagnostic tool for CAD $[9,10]$ in comparison to other international guidelines (ECS and American College of Cardiology/American Heart Association (ACC/ AHA)). With a new update in 2018 they eliminated routine pretest probability (PTP) calculation from CAD diagnostic algorithm. This enables CTA as a first-line test for patients with typical stable chest angina or atypical but with changes in electrocardiogram. If CTA results are indeterminable or non-diagnosable, same as ECS, NICE recommends to perform an additional test for ischemia evaluation. Only in the third place stands ICA with a condition, that previous tests results are uncertain. Overall, the guidelines update is orientated in cost-effectiveness and safety, lowering potential invasive test hazard. Despite ECS guidelines, focusing on benefit of functional testing, NICE recommendations are more sympathetic to anatomic testing. CTA based fractional flow reserve (FFR) is mentioned as an alternative diagnostic tool for both anatomy and myocardium ischemia evaluation. In this guidelines update CACS is presented as irrational test causing more harm caused by additional radiation, than clinical benefit.

\section{AHA/ACC}

Despite the fact, that these are the oldest and not yet updated guidelines, in 2012 United States scientific societies had included CTA in CAD diagnostic recommendations [11]. Target group of suspected CAD patients is with low to intermediate PTP. CTA as a choice for anatomical testing is recommended if prior testing results are normal, but typical symptoms persists or, as discussed earlier in two other guidelines, inconclusive functional testing results or unable to perform them. CACS calculation is used for asymptomatic patients with low to intermedium PTP, but recommendation are scientifically weak. In 2018, the updated AHA/ACC cholesterol management guidelines showed up with suggestion to use CACS as a risk predictor, when there are doubts about cholesterol lowering drug therapy initiation [12].

\section{Conclusion}

With newly published researches and meta-analysis, CTA becomes the most accurate non-invasive test for patients with low to intermedium PTP to detect obstructive CAD. Nevertheless, NICE already established CT for primary CAD diagnostic and eliminated PTP from diagnostic algorithm. While ESC and AHA/ACC guidelines point out the benefit of functional testing, CTA with additional FFR feature, combining anatomy and function in one exam, would be one step forward. All three guidelines favor CTA as second-line test after inconclusive functional testing. The CACS became a secondary test and is recommended only by ECS to rule-out CAD diagnosis and by AHA/ACC for determination of lipid lowering therapy. Today, despite seven-year gap, AHA/ACC guidelines resembles more to ECS than to NICE. With a new AHA/ACC guidelines update, CTA could become more usable in clinical practice and more popular for diagnosing CAD.

\section{References}

1. WHO (2008) The global burden of disease WHO, Geneva.

2. Knuuti J, Wijns W, Saraste A, Capodanno D, Barbato E, et al. (2019) 2019 ESC Guidelines for the diagnosis and management of chronic coronary syndromes: The Task Force for the diagnosis and management of chronic coronary syndromes of the European Society of Cardiology (ESC). European Heart Journal.

3. Knuuti J, Ballo H, Juarez Orozco L, Saraste A, Kolh P, et al. (2018) The performance of non-invasive tests to rule-in and rule-out significant coronary artery stenosis in patients with stable angina: a meta-analysis focused on post-test disease probability. European Heart Journal 39(35): 3322-3330.

4. Moschovitis A, Cook S, Meier B (2010) Percutaneous coronary interventions in Europe in 2006. Euro Intervention 6(2): 189-194.

5. Douglas P, Hoffmann U, Patel M, Mark D, Al Khalidi H, et al. (2015) Outcomes of anatomical versus functional testing for coronary artery disease. New England Journal of Medicine 372: 1291-1300.

6. The SCOT-HEART Investigators (2015) CT coronary angiography in patients with suspected angina due to coronary heart disease (SCOTHEART): an open-label, parallel-group, multicentre trial. The Lancet 385(9985): 2383-2391.

7. Karthikeyan G, Guzic Salobir B, Jug B, Devasenapathy N, Alexanderson E, et al. (2017) Functional compared to anatomical imaging in the initial evaluation of patients with suspected coronary artery disease: an international, multi-center, randomized controlled trial (IAEA-SPECT/ CTA study). Journal of Nuclear Cardiology 24(2): 507-517.

8. Budoff M, Mayrhofer T, Ferencik M, Bittner D, Lee K, et al. (2017) PROMISE Investigators, Prognostic value of coronary artery calcium in the PROMISE study (Prospective Multicenter Imaging Study for Evaluation of Chest Pain). Circulation 136(21): 1993-2005.

9. Kelion A, Nicol E (2018) The rationale for the primacy of coronary CT angiography in the National Institute for Health and Care Excellence (NICE) guideline (CG95) for the investigation of chest pain of recent onset. Journal of Cardiovascular Computed Tomography 12(6): 516-522. 
10. Dancy L, O'Gallagher K, Milton P, Sado D (2018) New NICE guidelines for the management of stable angina. British Journal of General Practice 68(669): 202-203.

11. Fihn S, Gardin J, Abrams J, Berra K, Blankenship J, et al. (2012) ACCF/ AHA/ACP/AATS/PCNA/SCAI/STS Guideline for the Diagnosis and Management of Patients with Stable Ischemic Heart Disease. Journal of the American College of Cardiology 60: 44-164.

ISSN: 2574-1241

DOI: 10.26717/BJSTR.2019.22.003767

Laura Zajančkauskienė. Biomed J Sci \& Tech Res

cC (P) This work is licensed under Creative Commons Attribution 4.0 License

Submission Link: https://biomedres.us/submit-manuscript.php
12. Grundy S, Stone N, Bailey A, Beam C, Birtcher K, et al. (2018) AHA/ ACC/AACVPR/AAPA/ABC/ACPM/ADA/AGS/APhA/ASPC/NLA/PCNA Guideline on the Management of Blood Cholesterol. Journal of the American College of Cardiology 73: 285-350.

$\begin{array}{ll}\text { BIOMEDICAL } & \text { Assets of Publishing with us } \\ \text { RESEARCHES } & \text { - Global archiving of articles } \\ & \text { - Immediate, unrestricted online access } \\ & \text { - Rigorous Peer Review Process } \\ & \text { - Authors Retain Copyrights }\end{array}$

